\title{
Diel vertical interactions between Atlantic cod Gadus morhua and sprat Sprattus sprattus in a stratified water column
}

\author{
Niels G. Andersen, Bo Lundgren, Stefan Neuenfeldt, Jan E. Beyer \\ Technical University of Denmark, National Institute of Aquatic Resources (DTU-Aqua), Charlottenlund Castle, \\ 2920 Charlottenlund, Denmark
}

\begin{abstract}
Information about species interactions at a spatial scale comparable to the perceptive abilities of the involved species is crucial for establishment of predictive food consumption models at the population level. Nevertheless, such information is sparse due to methodological constraints. We studied the diel vertical dynamics of species interactions between Atlantic cod Gadus morhua and its major clupeid prey, sprat Sprattus sprattus, at a location in the Bornholm Basin of the central Baltic Sea during late winter. This was accomplished by combining acoustic information on diel vertical fish distribution, time of ingestion of individual sprat estimated from cod stomach content data and observed vertical profiles of salinity, temperature and oxygen content. Predation by cod took place primarily at dusk and dawn during ascent and descent of sprat associated with school dissolution and formation, respectively. Cod resided close to the bottom outside these temporal predation windows. Sprat schools were located at the same depth as cod in the daylight hours, whereas at night dispersed sprat were situated higher in the water column. These vertical dynamics could be explained by fitness optimization using bioenergetics and trade-offs between temperature, oxygen saturation of the water and predation risk. This study forms a first step towards providing a mechanistic background for the predatory impact of cod at the basin scale and beyond.
\end{abstract}

KEY WORDS: Baltic Sea - Stomach content dynamics - Diel feeding cycle - Bioacoustics · Hydrography $\cdot$ Winter situation $\cdot$ Bioenergetics $\cdot$ Fitness optimization

\section{INTRODUCTION}

The predator-prey interactions between piscivorous and forage fishes are structuring elements in the dynamics of the ecosystem through trophic cascades (Paine 1980, Frank et al. 2005, Casini et al. 2009). A basic understanding of these interactions is therefore a prerequisite for studying ecosystem functioning in general, and an essential part of ecosystem-based fisheries management (Link 2010). Key variables in the marine environment such as light, temperature, salinity and oxygen are highly heterogeneous in space and time, which in turn influence the spatial distribution patterns of fish populations and their

${ }^{*}$ Corresponding author: nga@aqua.dtu.dk spatial overlaps. This creates spatial and temporal heterogeneity in small-scale predator-prey interactions that eventually produce the observed dynamics on population, community and ecosystem levels (Hunsicker et al. 2011).

Small-scale studies of species interactions in situ are sparse (Turesson \& Brönmark 2007, Kaartvedt et al. 2009), and it is in general difficult to obtain direct observations of interactions at the individual level in the sea with available technologies (Hunsicker et al. 2011). Information about prey composition obtained from sampled predator stomachs together with estimates of prey densities in the environment based on trawl catches have been used extensively to infer

(C) The authors 2017. Open Access under Creative Commons by Attribution Licence. Use, distribution and reproduction are unrestricted. Authors and original publication must be credited. 
feeding behaviour and functional response of predators (Floeter \& Temming 2003, Rindorf et al. 2006). The geographic scale at which this information should be compared has been discussed by several authors (Rose \& Leggett 1990, Englund \& Leonardsson 2008). Usually, the applied scale is much larger than the perceptive ability of the species involved. The biological mechanisms behind the findings of these studies are therefore open for liberal interpretation. As long as the small-scale mechanisms that give rise to a specific observed functional response at a larger scale are unknown, the results obtained from large-scale sampling are hardly useful for extrapolations to new situations such as future scenarios enforced by climate changes.

The central Baltic Sea is among the largest brackish waters in the world and consists of a number of deep basins, all of which show pronounced vertical stratification of the water column. Low salinity surface water is separated by a halocline from deep water of higher salinity. Irregular inflows of saline water from the North Sea renew the deep water. Hypoxia is prominent after longer stagnation periods without inflow events, and the level of dissolved oxygen is an important driver of fish stock dynamics. The fish community in the Baltic Sea is dominated by Atlantic cod Gadus morhua and its 2 major prey species, herring Clupea harengus and sprat Sprattus sprattus, making predator-prey interactions relatively easy to studyespecially because since its outburst in the late 1980s, sprat has become by far the most important planktivorous fish there (Köster et al. 2001).

Neuenfeldt \& Beyer (2006) considered the effects of the vertical spatial overlaps of cod and its clupeid prey on the aggregate diet of cod in the Bornholm Basin of the Baltic Sea. They showed that the ratio of herring to sprat consumed by cod decreased more slowly than did the abundance ratio in the environment during the decline of the cod stock in the 1980s, and concluded that without understanding the cod-clupeid overlaps, the observed diet composition dynamics could be misinterpreted as a situation of negative switching. Neuenfeldt \& Beyer (2006) only considered the vertical distribution during daytime and disregarded the diel vertical migration (DVM) of the clupeids with schooling close to the bottom during daytime, ascending and dispersing at dusk, and descending and aggregating again at dawn (Cardinale et al. 2003, Nilsson et al. 2003).

Three major mechanisms involving foraging, predator avoidance, and bioenergetics have been hypothesized to explain adaptation of the DVM behaviour in pelagic planktivorous fish (Clark \& Levy 1988). The foraging hypothesis suggests that planktivorous fish follow the DVM of zooplankton to optimize their feeding conditions. According to the predator avoidance hypothesis, DVM of both planktivores and zooplankton is believed to be the outcome of the evolutionary race between predator and prey, where the prey follow the 'antipredation window' at levels of light intensity occurring at dusk and dawn (Clark \& Levy 1988, Scheuerell \& Schindler 2003). Here, the visual searching ability of their predators (and so predation mortality) is reduced and the ratio of predation risk to food consumption rate minimized (Eggers 1978, Levy 1990a, Rosland \& Giske 1994). The bioenergetics hypothesis has been used to explain vertical behaviour under different feeding conditions as a motivation to migrate to water temperatures where energy conservation or accretion is optimized. In cases of food limitation, colder water is preferred to reduce metabolic rate and maximize food conversion efficiency (Brett 1971). Alternatively, under favourable feeding conditions the fish are expected to seek warmer water to accelerate food processing and, thus, growth rate (Wurtsbaugh \& Neverman 1988, Levy 1990a,b, Neverman \& Wurtsbaugh 1994, Orlowski 2000).

Cardinale et al. (2003) found that clupeids in the Bornholm Basin performed DVMs during the feeding season. They related this behaviour to all 3 hypotheses. Cod predation on the clupeids was, however, inferred but not observed. Using hydroacoustics information, Nilsson et al. (2003) found that sprat also performed DVMs in late winter, when they are food limited or do not feed at all (Arrhenius 1998).

Due to limited knowledge about the dynamics of predator-prey interactions, a mechanistic understanding of cod predation on clupeids at small temporal and spatial scales needs to be addressed in the Baltic Sea. The aim of this study was to examine the vertical predator-prey interactions between cod and sprat, and to identify the possible drivers. Attention was restricted to a water column examined during a vessel survey in late winter in the Bornholm Basin of the central Baltic Sea (Nilsson et al. 2003). This should ensure almost constant environmental conditions; the challenge was how the diel light conditions together with other physical and biological variables influenced the behaviour of both species and their interactions in the stratified water column (Blaxter 1975, Lampert \& Sommer 2007). The observed behavioural dynamics and interactions of predator and prey are explained in terms of fitness optimization using bioenergetics and trade-offs between temperature, oxygen saturation of the water, food acquisition and predation risk (e.g. Rosland \& Giske 1994). 


\section{MATERIALS AND METHODS}

The vertical distribution dynamics of cod and sprat were described by use of hydroacoustics data sampled during a trawl survey of the Baltic Sea in 2002. The diel feeding pattern of cod was established using information about contents in sampled stomachs, input into a gastric evacuation rate (GER) model that enabled estimation of ingestion times of individual sprat. To run the GER model, specimens of the main prey of cod were sampled for measurements of length, mass and energy density. The cod energy balance was assessed using the GER model to prey and stomach data for estimation of food consumption rate. Also, the energy balance of sprat was evaluated by examination and quantification of stomach contents of sampled sprat. The physical variables salinity, temperature and oxygen saturation were described by data from CTD profiling.

\section{Field sampling}

\section{Study area}

The $\sim 5 \mathrm{~km}^{2}$ sampling area was located in the northeastern part of the Bornholm Basin $\left(55^{\circ} 45.000^{\prime}\right.$ to $55^{\circ} 48.457^{\prime} \mathrm{N}, 16^{\circ} 20.210^{\prime}$ to $16^{\circ} 20.980^{\prime} \mathrm{E}$ ), at depths of 61.5 to $65.5 \mathrm{~m}$ (Fig. 1). The typical depth of the Bornholm Basin is 60 to $80 \mathrm{~m}$ with a maximum depth of $105 \mathrm{~m}$.

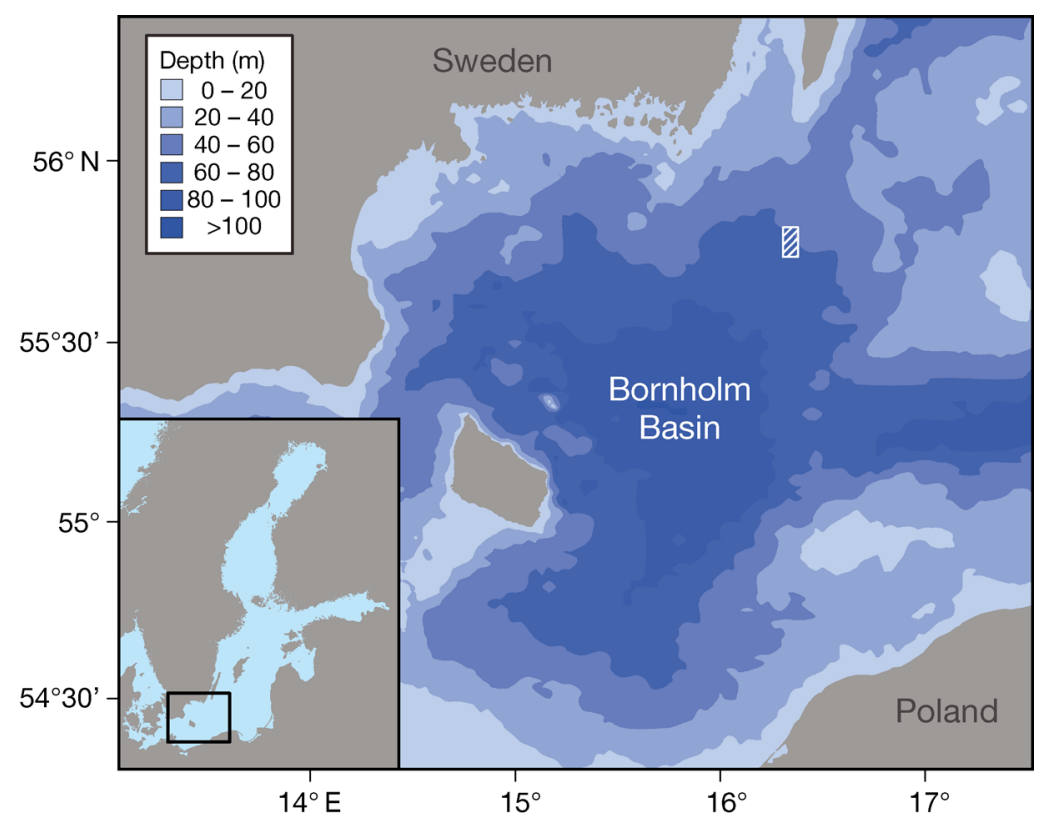

Fig. 1. Sampling site (white, hatched rectangle) in the northeastern area of the Bornholm Basin, central Baltic Sea
Sampling of biological materials

In continuance of the first of the 2 annual international trawl surveys in the Baltic Sea (BITS) in 2002, cod, herring and sprat were obtained from 16 trawl hauls undertaken every $3 \mathrm{~h}$ from 12 to 14 March onboard the Danish RV 'Dana' (see Table 1). The BITS gear setup and fishing procedure were followed (http:// doi.org/10.17895/ices.pub.2883), using a TV3 bottom trawl with $16 \mathrm{~mm}$ cod-end, fishing speed of $\sim 2.5$ knots and towing time of ca. $30 \mathrm{~min}$. The vertical gap of the trawl was $5.4 \pm 0.4 \mathrm{~m}$ (mean $\pm \mathrm{SD}$ ) and the (horizontal) spread between the otter boards $\sim 100 \mathrm{~m}$. The catch from each haul was processed to obtain total number and size distribution by fish species as specified in the BITS protocol. In addition, 4 pelagic $1 \mathrm{~h}$ hauls were carried out in the dark hours between $17: 00 \mathrm{~h}$ on 14 March and 02:00 h on 15 March by use of an EXPO trawl that covered the depth interval of 37 to $50 \mathrm{~m}$. The environmental conditions during this night were comparable to those of the 2 preceding nights, and it is therefore assumed that the results were as well.

On 13 March, local civil twilight started at 04:39 h, sunrise and sunset times were 05:16 and 16:54 h, and civil twilight ended at 17:30 h (UTC). Moonrise and moonset times were 05:46 and 16:00 h (new moon) (http://aa.usno.navy.mil/data/docs/RS_OneDay.php). The sky was clear most of the time.

From each bottom trawl catch, 15 to 51 stomachs of cod within the length range of 38 to $54 \mathrm{~cm}$ (most 38 to $48 \mathrm{~cm}$ ) were excised (see Table 1), individually packed in plastic bags and transferred to a tunnel freezer $\left(-18^{\circ} \mathrm{C}\right)$. Invalid stomachs (with signs of regurgitation according to the criteria set up by ICES 1991) were discarded and replaced by valid non-empty stomachs. Otherwise, estimation of food consumption rates would be underestimated due to overrepresentation of empty stomachs (Hislop et al. 1991). In addition, 20 sprat (length range 9 to $13 \mathrm{~cm}$ ) were selected from each trawl haul and frozen for later examination of their stomach contents. Individuals of sprat $(\mathrm{n}=294 ; 10$ to $14 \mathrm{~cm}$ ), herring ( $\mathrm{n}=147 ; 15$ to $22 \mathrm{~cm}$ ) and the isopod Saduria entomon ( $\mathrm{n}=60 ; 2.8$ to $5.4 \mathrm{~cm}$ ), evenly distributed within the body length ranges, were collected and frozen for later measurements of length, body mass and energy density. Finally, to correct lengths of prey recovered from the cod stomachs when comparing length distributions of prey in the stomachs with 
those in the trawl hauls, 20 sprat $(11 \mathrm{~cm})$ and 20 herring $(18 \mathrm{~cm})$ were measured for length, individually bagged and frozen. The lengths of these individuals were measured once again after thawing to calculate shrinkage due to the freezing procedure.

\section{Hydrography}

A total of 9 vertical profiles of salinity, temperature and oxygen saturation were obtained immediately before or after most trawl stations with a Sea-Bird 911 CTD system that recorded conductivity, temperature, pressure (depth) and oxygen partial pressure. The CTD system was mounted on a SBE 32 bottle sampler with 41 bottles used to collect water at different depths. Subsamples were transferred to specially designed salinity and oxygen bottles according to standard procedures, and oxygen concentrations were measured onboard by the Winkler titration method (Ducklow \& Dickson 1994) to calibrate the CTD measurements. Salinity samples were stored and conductivity measured after the cruise using a Portasal 8410B salinometer (Guildline; www.guildline.com/ oceanography/salinometers/salinity-measurement/ 8410a-portasal-portable-salinometer) to check the salinity measurements (Ducklow \& Dickson 1994). CTD raw data were processed by use of the SBE Data Processing package version 7.20g (Sea-Bird Scientific; www.seabird.com/sbe911plus-ctd). The Sea-Bird system was furthermore equipped with a light sensor (Biospherical/Licor) to measure photosynthetically active radiation (PAR).

\section{Hydroacoustics}

Hydroacoustics data were collected continuously during the cruise period using a Simrad EY500 echosounder with $38 \mathrm{kHz}$ transmit frequency, which was connected to the ES38B transducer $\left(7^{\circ}\right.$ beam width) mounted at $\sim 6 \mathrm{~m}$ depth in a transducer blister on the hull of the vessel. External power supply was used to increase the transmit pulse power to $2000 \mathrm{~W}$; the pulse rate was 1 ping s ${ }^{-1}$, and pulse length was set at $1.0 \mathrm{~ms}$. The echosounder was run by the Simrad EY500 software and stored in the Simrad EY DG-file format (Simrad EY500 Instruction Manual). The echosounder was calibrated using a standard $60.0 \mathrm{~mm}$ diameter copper sphere in June 2001 at a location near Bornö Island in Gullmar Fjord, Sweden, and again at the same location in June 2002. The measured transducer gain decreased by $<2 \%$ (from
25.1 to $24.6 \mathrm{~dB}$ ), indicating that the performance of the echosounder had been stable between calibrations.

\section{Laboratory analyses of sampled biological materials}

Cod stomachs were thawed in the laboratory on land, their contents identified to the lowest taxonomic level possible. Each prey item was dabbed with a moistened paper towel, and weighed and measured for length. Length measurements of fish included total length, standard length and reduced standard length (standard length - head = length of vertebral column). Fish prey that could not be measured due to advanced state of digestion were given the mean lengths of their measured conspecifics. Total length and length of the pleotelson of $S$. entomon as well as total length of mysids were measured. The mass of detached prey remains that could not be assigned to any particular prey were allocated to the identified prey items in proportion to their respective surface contributions to total stomach contents according to the GER model used here (see the Supplement at www.int-res. com/articles/suppl/m583p195_supp.pdf) to estimate prey ingestion times and food consumption rates (Andersen \& Beyer 2008a).

The fresh sprat, herring and $S$. entomon prey collected for morphometric measurements were thawed in the laboratory, length measured (same as above) and individually weighed. The energy densities of all $S$. entomon together, and sprat and herring grouped in 8 length classes $(0.5$ and $1 \mathrm{~cm}$ intervals, respectively), were thereafter determined by bomb calorimetry in an IKA-7000 bomb calorimeter (www. ika.net) following the procedures described in Pedersen \& Hislop (2001). Values were corrected for carbonate content (Paine 1966) as well as nitric acid produced during combustion (Golley 1961). The 20 sprat per trawl haul used for stomach content examination were thawed, the stomachs excised and the recovered contents identified to the lowest possible taxonomic level and weighed.

\section{Data processing and analyses}

\section{Hydroacoustics}

The editable lines facility in Echoview version 4.6 (https://www.echoview.com) was used to select valid data. An upper limit line was initially set at $3 \mathrm{~m}$ below 
the near-field of the transducer corresponding to $9 \mathrm{~m}$ from the surface. This line was then edited manually to exclude invalid data due to propeller noise or bubbles generated by bow thrusters, other vessels or breaking waves. According to standard procedure to avoid inclusion of bottom echoes, a lower limit line was created with a safety margin of $0.5 \mathrm{~m}$ above the bottom line generated by the echosounder. This line was then edited manually to correct errors where the echosounder had included soft bottom or excluded fish schools. The near-bottom dead zone of the echosounder was approximately $0.11 \mathrm{~m}$ at $60 \mathrm{~m}$ depth and with a $7^{\circ}$ beam width. Data recorded while the vessel was stationary during CTD-profiling operations were discarded.

The data preprocessed by Echoview were shown as echograms in 3 different display modes. The first mode $(20 \log R)$ displays volume backscattering strength, $S_{V}$ at different depths (distances $R$ ) (see Fig. 5). The second mode (40 $\log R$ ) shows data used for single target detection by the Single-targets Method 1 operator in Echoview. The third mode shows the resulting target strength (TS) data and was used to visually inspect detected single targets for further elimination of invalid data overlooked in the previous process.

TS values, compensated for the angular position of each target in the beam, together with the variables time, GPS data, echo depth and bottom depth were exported to Excel. Here, the single targets representing sprat and cod were used to examine their diel vertical distribution dynamics. Data were grouped in $40 \mathrm{~min}$ intervals and the distance to the bottom of the $20^{\text {th }}, 50^{\text {th }}$ and $80^{\text {th }}$ percentiles was calculated. Using the standard slope 20 (Foote 1987), TS ranges representing the 2 species were estimated as TS $=20 \log L$ $+b_{20}(\mathrm{~dB})$ where $L(\mathrm{~cm})$ is total fish length, and the species-specific parameter $b_{20}$ is the TS of a $1 \mathrm{~cm}$ long fish. The general value $-71.2 \mathrm{~dB}$ of $b_{20}$ for sprat and herring obtained in high-saline waters and used in the Baltic International Acoustic Survey (ICES 2009) is probably too low for fishes in the eastern Baltic Sea. This is primarily because the fish need a larger swimbladder volume to obtain neutral buoyancy due to the lower salinity here, which implies that the value of $b_{20}$ is higher (Didrikas \& Hansson 2004, Fässler et al. 2008). To estimate $b_{20}$, the distribution of TS in the dark hours with dispersed fish was related to the length distribution of sprat as the dominant species in the trawl catches. No distinct peak in the TS distribution could be obtained from cod. The commonly used value $-67.4 \mathrm{~dB}$ of $b_{20}$ for cod (Foote 1987) was therefore displaced by the same value as the difference between $-71.2 \mathrm{~dB}$ and the estimate of $b_{20}$ obtained for sprat in this study.

\section{Estimation of prey ingestion times and food consumption rates}

The time between sampling and ingestion of each prey in the cod stomach was estimated using a GER model to hindcast the recovered prey mass to its original body mass (Griffith 1976), the latter being estimated from observed prey length and the relationship between prey length and fresh body mass. Sampling time was set at the middle of the trawl haul period, because digestive processes are likely to stop in the trawl due to the struggling behaviour of the fish (Farrell et al. 2001). The mechanistic, surfacedependent cylinder GER model advanced by Andersen \& Beyer $(2005 \mathrm{a}, \mathrm{b})$ and validated in a suite of experiments (see references in Andersen et al. 2016) was used here. This implies that the GER of each individual prey at any time is proportional to its exposed surface for the present prey composition in the stomach. In addition, apart from temperature and cod length, the GER depends on the prey item's resistance to the digestive processes, prey length and remaining prey body mass, and the energy density of the currently evacuated prey materials. Model parameter values for cod (Andersen 2012) as well as prey morphometry and energy densities achieved in the present study were used in the hindcasting procedure, which also allows for estimation of the variances of the ingestion times obtained. All details are provided in the Supplement at www.int-res.com/ articles/suppl/m583p195_supp.pdf.

Two approaches were used to estimate food consumption rates and feeding levels of cod based on the cylinder GER model. First, total GER $\left(\mathrm{kJ} \mathrm{h}^{-1}\right)$ was estimated for each stomach by summing all individual prey GER $\left(\mathrm{g} \mathrm{h}^{-1}\right)$ contributions at the time of sampling multiplied by the prey-specific energy densities (see the Supplement). Following the principle that, averaging over time and population, mean consumption rate equals mean GER (e.g. Pennington 1985), the daily ration was estimated as the mean total GER $\left(\mathrm{kJ} \mathrm{h}^{-1}\right)$ multiplied by $24 \mathrm{~h}$. Second, estimating the number of prey ingested within a predefined period of time prior to stomach sampling by use of a GER model to stomach content data, Johansen et al. (2004) quantified the consumption of herring by cod in the Barents Sea. In the present study, the output from the estimation of prey ingestion times was used to estimate the amount of prey 
energy ingested by each sampled cod during the latest full feeding period (dusk-night-dawn) prior to stomach sampling. This also represents the daily ration, and the mean value was calculated from all cod. The 2 approaches can be considered independent methods because of the shift in focus from instantaneous GER at one point in time to the number of prey consumed over a period of time, which has been chosen independently of the number of prey observed in the stomach at sampling. Thus the methods not only use different parts of the data for each stomach, but they also use them differently. Different results would therefore indicate possible inconsistences in data or violations of respective assumptions.

To evaluate the energy balance status of the sampled cod, and to standardize the daily ration, $C$, with regard to cod size, the latter was expressed by the feeding level $f=$ $C C_{\max }^{-1}$ where the maximum sustained consumption rate, $C_{\max }=0.223$ $\exp \left(0.104 T-0.000112 T^{3}\right) M^{0.802}(\mathrm{~kJ}$ $\mathrm{d}^{-1}$ ), was established by Jobling (1988) from data on satiation rations of capelin Mallotus villosus fed to a cod of body mass $M(\mathrm{~g})$ at temperature $T\left({ }^{\circ} \mathrm{C}\right)$ (Johnsen 1981, Braaten 1984).

The $95 \%$ CIs of the mean $f$ obtained from the 2 approaches were estimated, and the difference between the means was tested for significance in $\mathrm{R}$ ( $\mathrm{R}$ Core Team 2016). The means were considered equal if $\mathrm{p}>0.05$ (Basic, non-parametric bootstrapping cf. Efron \& Tibshirani 1993) .

\section{RESULTS}

\section{Hydrography}

The vertical profiles of salinity, temperature and oxygen saturation obtained from the 9 CTD stations were similar, and therefore averaged into a generalized profile (Fig. 2) for comparison with the speciesspecific vertical fish distributions obtained from hydroacoustics. The profile showed a typical winter situation in a stagnant period with no recent intrusion of saline water from the North Sea. The top layer of water extended down to $\sim 8 \mathrm{~m}$ above the bottom and was uniform with low temperature $\left(3^{\circ} \mathrm{C}\right)$ and salinity ( $7 \mathrm{psu}$ ) and high oxygen saturation (93\%). Towards the bottom in the combined halo-, thermoand oxycline, the salinity and temperature increased to $13.5 \mathrm{psu}$ and $8^{\circ} \mathrm{C}$, and oxygen saturation decreased to below $25 \%$.

From the Sea-Bird PAR data, Nilsson et al. (2003) estimated the diffuse attenuation coefficient to vary between 0.131 and $0.167 \mathrm{~m}^{-1}$, and used a value of $0.16 \mathrm{~m}^{-1}$ together with a model for surface illuminance to calculate local light intensities in the water column. At dusk, the schools of sprat detected by hydroacoustics ascended following the lines of equal light levels between $2 \times 10^{-2}$ and $2 \times 10^{-3} \mu \mathrm{mol}$ quanta $\mathrm{m}^{-2} \mathrm{~s}^{-1}$ and gradually dissolved below these lines causing a widening of the vertical dispersed distribution of fish (see Nilsson et al. 2003 for details).

\section{Trawl catches}

In the daylight hours, when the fishes were situated close to the bottom and thus within reach of the trawl, sprat was the dominant fish in the trawl catches comprising $96.7 \%$ of the total number of fish 

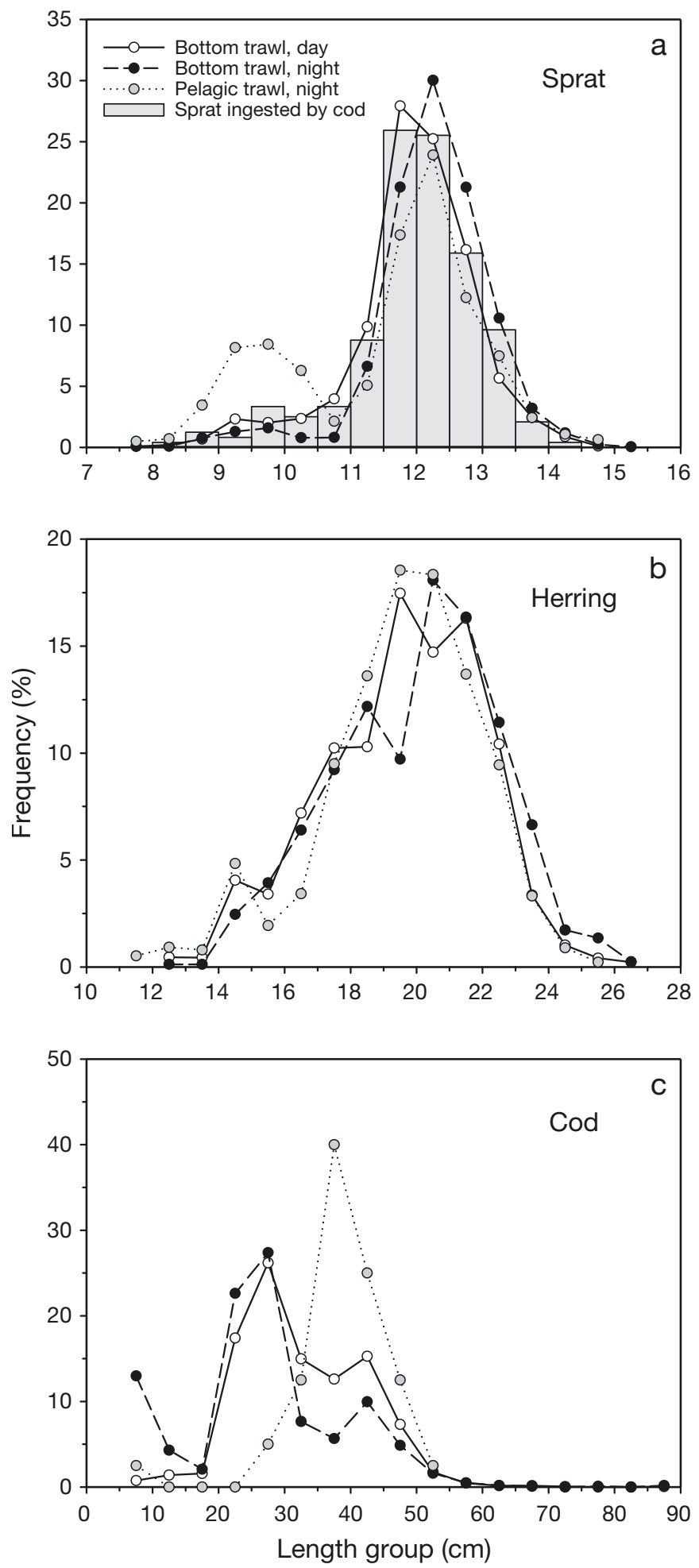

Fig. 3. Size distributions of (a) sprat Sprattus sprattus, (b) herring Clupea harengus and (c) Atlantic cod Gadus morhua caught by bottom trawling in the light hours $\left(\mathrm{n}_{\mathrm{a}}=\right.$ $\left.259941, \mathrm{n}_{\mathrm{b}}=7080, \mathrm{n}_{\mathrm{c}}=2024\right)$ and dark hours $\left(\mathrm{n}_{\mathrm{a}}=19779, \mathrm{n}_{\mathrm{b}}\right.$ $\left.=813, \mathrm{n}_{\mathrm{c}}=1256\right)$, and by pelagic trawling in the dark hours $\left(\mathrm{n}_{\mathrm{a}}=86967, \mathrm{n}_{\mathrm{b}}=4033, \mathrm{n}_{\mathrm{c}}=40\right)$. Columns in (a) indicate the size distribution of sprat ingested by the sampled cod $(\mathrm{n}=249)$ caught, whereas herring and cod only comprised 2.6 and $0.7 \%$, respectively (Fig. 3). Converted to biomass, sprat still accounted for $80 \%$ and herring and cod amounted to $10 \%$ each. The share of other species was consequently insignificant.

The trawled sprat ranged in length from 7.5 to $14.5 \mathrm{~cm}$ with a peak at $12 \mathrm{~cm}$ (Fig. 3a). The size distribution of sprat obtained by bottom trawling did not differ between night and day. In the dark hours, however, the pelagic catches above the halocline displayed another peak composed of smaller individuals (9 to $10 \mathrm{~cm}$ ) representing young-of-the-year (YOY) sprat, which was consistent for all pelagic hauls. As a result, the proportions of sprat $<11 \mathrm{~cm}$ in catches obtained from pelagic and bottom trawling at night were significantly different (z-test for 2 population proportions, $z=70.8, \mathrm{p}<0.0001$ ).

The size distribution of herring ranged from 12 to $25 \mathrm{~cm}$ with the most abundant sizes between 17 and $23 \mathrm{~cm}$; the size overlap with sprat was slight (Fig. 3b). The size range of cod caught by bottom trawl was 7 to $85 \mathrm{~cm}$ with only few individuals above $55 \mathrm{~cm}$. The distributions displayed 2 peaks at 20 to $30 \mathrm{~cm}$ and 40 to $45 \mathrm{~cm}$, as well as a third one for the smallest cod in the dark hours (Fig. 3c). In contrast, smaller cod were almost absent in the pelagic catches and the distribution of the cod obtained from pelagic trawling peaked at 35 to $45 \mathrm{~cm}$.

\section{Hydroacoustics}

The echograms primarily reflected the behavioural dynamics of sprat that dominated by number and biomass. The daytime situation was characterized by schools of fish located close to the bottom (Fig. 4a). The dense layer of fish seemed, however, to stay clear of the bottom at larger depths. At dusk between 17:00 and 18:00 h, fish schools ascended whilst other schools left below dispersed, resulting in a gradual extension of the vertical distribution well above the halocline into the upper uniform water layer (Fig. 4b) (see also Nilsson et al. 2003). The fish remained dispersed in the water column throughout night until dawn between 04:25 and 05:25 h, where the reversed process of school formation and descent re-established the daytime pattern.

The frequency distribution of TS of all single targets displayed a distinct peak at $-42 \mathrm{~dB}$ (Fig. 5), which was consistent between sub-sections of the acoustic track. Related to the $12 \mathrm{~cm}$ peak of the length distribution of sprat caught by trawling (Fig. 3a), this TS peak provided $b_{20}=-63.9 \mathrm{~dB}$ 

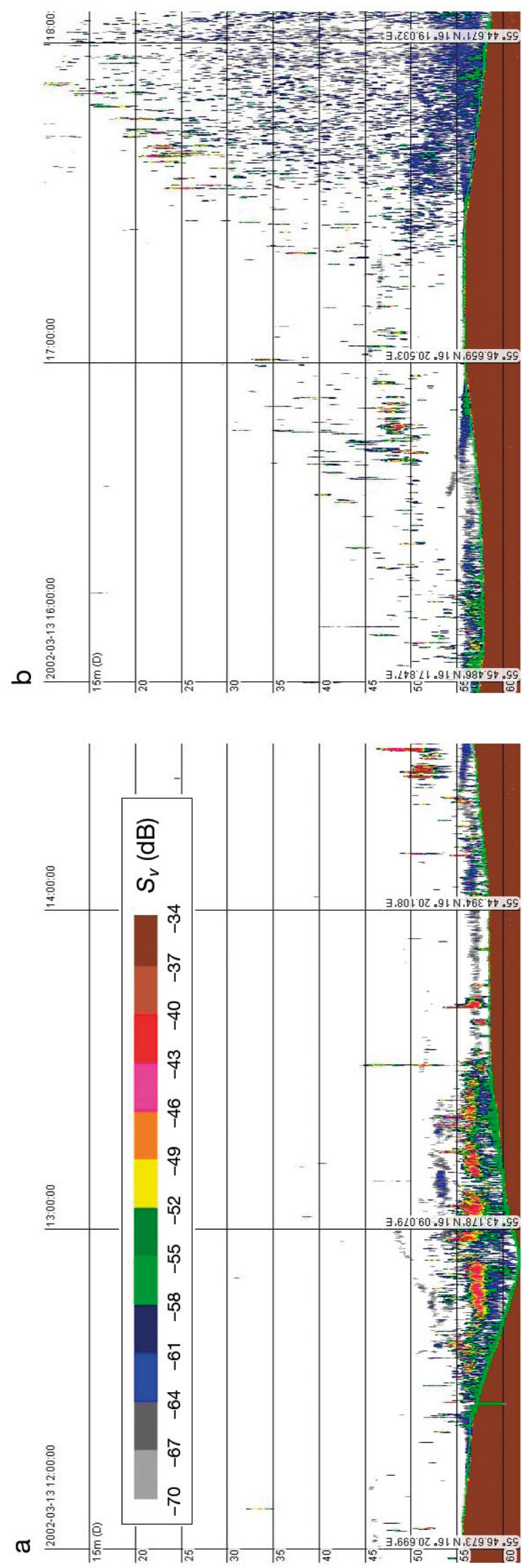

from the $L$-TS relationship (i.e. a displacement of $7.3 \mathrm{~dB}$ from the value of $-71.2 \mathrm{~dB}$ used in ICES 2009). This $b_{20}$ value implies $\mathrm{TS}=-38 \mathrm{~dB}$ for the $\sim 20 \mathrm{~cm}$ peak of the herring length distribution (Fig. 3b), which may explain the hump on the distribution curve just to the right of the sprat peak in the TS distribution (Fig. 5). For $\operatorname{cod}, b_{20}=-60.1 \mathrm{~dB}$ was obtained by use of the same displacement as for sprat. Using the species-specific values obtained, the single targets of strengths from -46 to $-41 \mathrm{~dB}$ representing 7.5 to $14 \mathrm{~cm}$ sprat, and from -30 to $-24 \mathrm{~dB}$ covering 30 to $60 \mathrm{~cm}$ cod were selected to describe the diel vertical distribution dynamics of these 2 species. The peak at $-60 \mathrm{~dB}$ (Fig. 5) within the TS range of small organisms, which also was consistent between sub-sections of the acoustic track, probably represents mysids that form layers close to the bottom.

Based on the observed single targets, the vertical distribution of sprat showed a distinct diel pattern (Fig. 6a). They stayed close to the bottom below the uniform surface layer during daytime and ascended in the period between $17: 00$ and $18: 00 \mathrm{~h}$ to cover more than half the water column throughout the dark hours before descending again between 04:25 and 05:25 h. These vertical distribution dynamics of sprat reflected the pattern appearing on the $20 \log R$ echograms (Fig. 5).

Like sprat, cod stayed close to the bottom during the daylight hours and made ascents at dusk synchronously with sprat, but apparently of short dura-

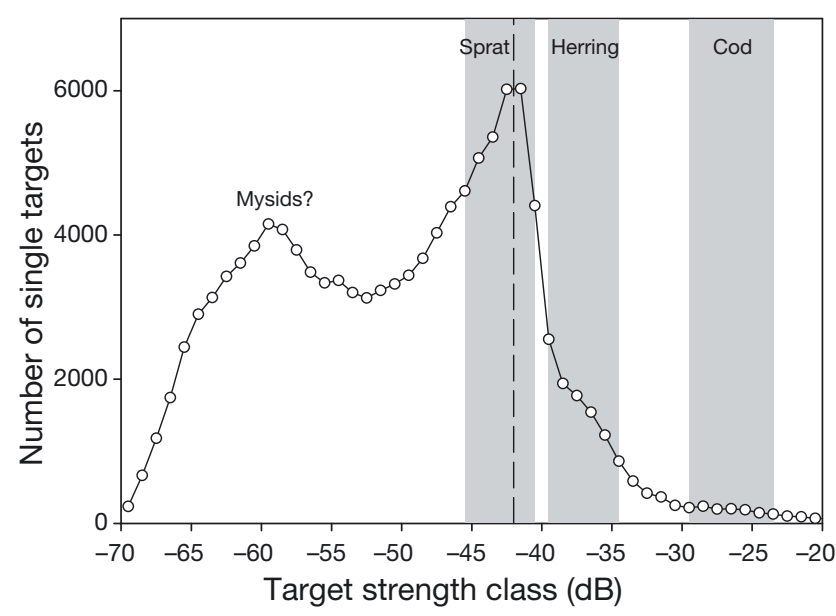

Fig. 5. Total number of single targets in each $1 \mathrm{~dB}$ target strength class obtained from backscatter data by use of hydroacoustics. The dashed vertical line at $-42 \mathrm{~dB}$ indicates sprat Sprattus sprattus of total length $12 \mathrm{~cm}$ (Fig. 3). Grey shading: target strength ranges of sprat $(7$ to $14 \mathrm{~cm}$ ), herring Clupea harengus (17 to $23 \mathrm{~cm}$ ) and Atlantic cod Gadus morhua (30 to $60 \mathrm{~cm}$ ) 
tion (Fig. 6b). Further ascents appeared to be going on during the night, though at times the data here were sparse. Cod made a brief ascent again at dawn in the period where the sprat moved downward. At daytime, the mean distance from cod to bottom was $3.4 \mathrm{~m}$ at $5.5^{\circ} \mathrm{C}$ and $64.2 \% \quad \mathrm{O}_{2}$ saturation (Fig. 2). Assuming that digesting cod were residing here, this local temperature was used to estimate prey ingestion times and food consumption rates by use of the GER model to stomach content data.

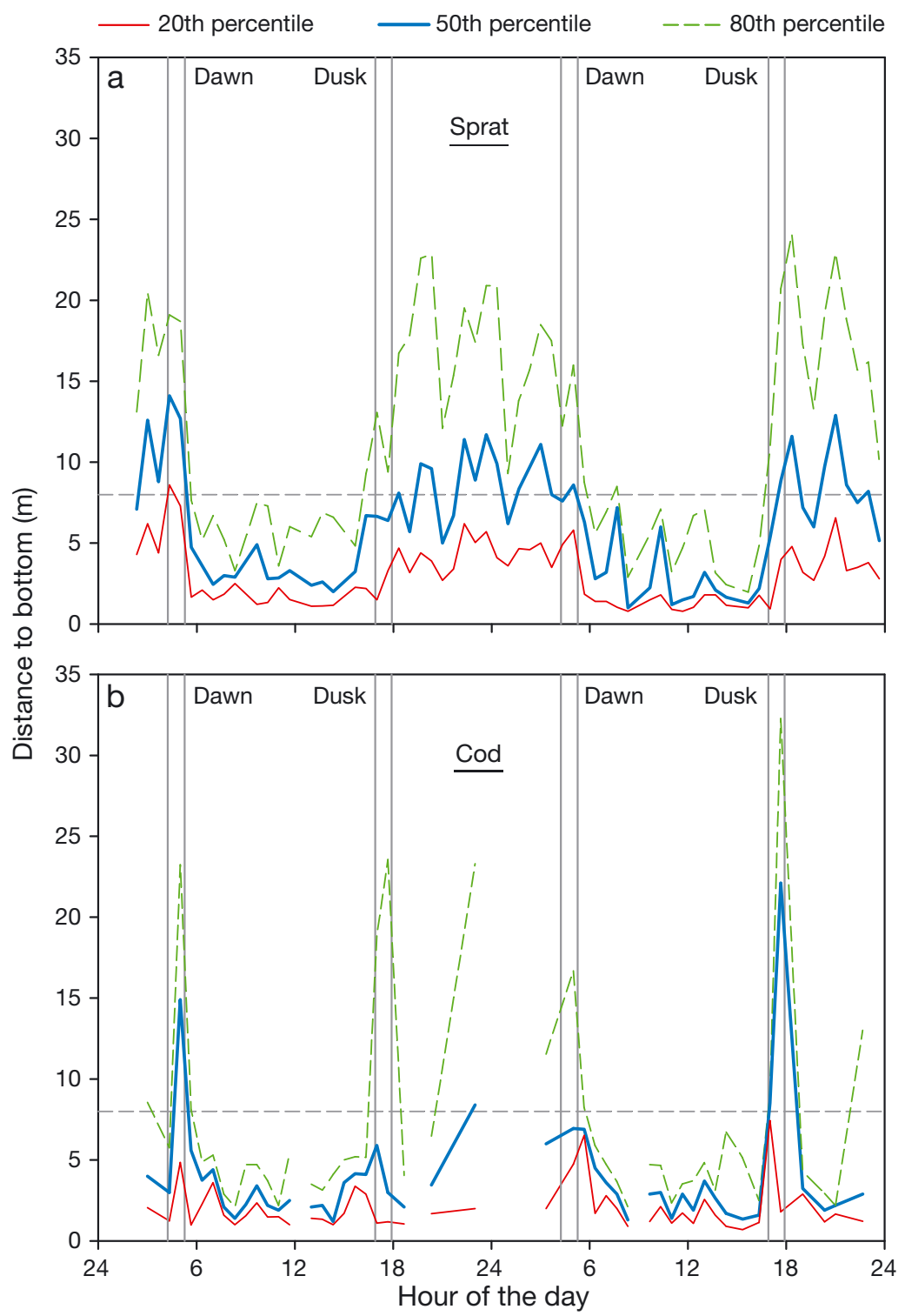

Fig. 6. Diel dynamics of the vertical distribution of single targets of strengths between (a) -46 and $-41 \mathrm{~dB}$ interpreted as sprat Sprattus sprattus ( $\mathrm{n}=27430)$ and (b) -30 and $-24 \mathrm{~dB}$ interpreted as Atlantic cod Gadus morhua $(\mathrm{n}=1208)$. Curves are $20^{\text {th }}, 50^{\text {th }}$ and $80^{\text {th }}$ percentiles for each $40 \mathrm{~min}$ period. The gaps for cod indicate missing or few $(<10)$ observations in a period. Horizontal dashed line: bottom of the uniform top layer of the $\sim 64 \mathrm{~m}$ water column; pairs of vertical lines define dawn and dusk

\section{Cod stomachs}

The number of cod stomachs differed between sample times (Table 1), and to avoid bias when examining the diel feeding pattern, the period hindcasted for each cod stomach should represent a multiple of $24 \mathrm{~h}$. Also, it is a prerequisite for an unbiased result (and without excessive uncertainties) that all ingestion times in the period are based on prey with observable lengths (Andersen \& Beyer 2008b). These conditions restricted the hindcasted period to $24 \mathrm{~h}$, and the diel feeding pattern obtained from the estimated ingestion times of sprat $(\mathrm{n}=194)$ showed a distinct pattern with peaks at dusk and dawn (Fig. 7). Using $95 \%$ CIs of the estimated ingestion times, it could not be rejected that $87.1 \%$ of the sprat were ingested at dusk $(39.7 \%)$ or dawn $(47.4 \%)$. Similarly, $12.4 \%$ were ingested during night and one sprat during daytime.

The feeding level $f$ obtained from the mean GER was 0.40 (95\% CI: 0.37 to $0.43 ; 492$ stomachs). The fractions made up by sprat, herring, Saduria entomon, Mysis mixta and other prey in the diet of cod were 93.0, 5.3, 1.0, 0.4 , and $0.2 \%$ energy. Other prey were sandeel Ammodytes tobianus and sand goby Pomatoschistus minutus.

The indicated feeding pattern of cod that included a feeding pause during daytime (Fig. 7), enabled the alternative estimate 0.39 (0.32 to $0.45 ; 492$ stomachs) of $f$ by accounting for the energy contained in all the prey ingested by each sampled cod during the latest full feeding period (dusk-night-dawn) prior to stomach sampling. This value was close to the estimate based on mean GER ( $p>0.74)$. A total of 162 stomachs, equivalent to $33 \%$ of the total number of stomachs, contained prey ingested during this period. The fractions constituted by sprat, herring, S. entomon, M. mixta and other prey in the diet of cod were $90.0,8.7,1.2,0.1$ and $0 \%$ energy.

Correcting for shrinkage of $4.9 \% \pm 0.9$ (SD) due to the freezing procedure, the size distribution of ingested sprat with observable lengths matched the distribution of sprat obtained by bottom trawling (Fig. 3a). The size range of in- 
Table 1. Total number of cod stomachs (empty stomachs in parentheses) and associated cod total body length and mass (mean $\pm \mathrm{SD}$ ) by bottom trawl station, sampled in the Bornholm Basin of the Central Baltic Sea (30 min trawl haul with indicated date, start time and water depth)

\begin{tabular}{|c|c|c|c|c|c|}
\hline Station & $\begin{array}{l}\text { Start time } \\
\quad(\mathrm{UCT})\end{array}$ & $\begin{array}{c}\text { Mean } \\
\text { depth }(\mathrm{m}\end{array}$ & $\begin{array}{l}\text { Length } \\
\text { a) }(\mathrm{cm})\end{array}$ & $\begin{array}{l}\text { Mass } \\
\text { (g) }\end{array}$ & $\begin{array}{c}\text { Stomachs } \\
\text { (n) }\end{array}$ \\
\hline \multicolumn{6}{|c|}{12 March 2002} \\
\hline 1 & $02: 36$ & 65.5 & $43.0 \pm 2.9$ & $783 \pm 160$ & $40(6)$ \\
\hline 2 & $05: 18$ & 65.5 & $42.3 \pm 2.4$ & $780 \pm 161$ & $38(7)$ \\
\hline 3 & $08: 23$ & 65.0 & $41.9 \pm 2.7$ & $739 \pm 156$ & $35(10)$ \\
\hline 4 & $11: 18$ & 64.5 & $41.4 \pm 2.4$ & $713 \pm 134$ & $17(4)$ \\
\hline 5 & $14: 20$ & 63.5 & $41.7 \pm 2.3$ & $748 \pm 138$ & $50(17)$ \\
\hline 6 & $17: 15$ & 61.5 & $41.5 \pm 2.4$ & $730 \pm 151$ & $28(6)$ \\
\hline 7 & $20: 12$ & 62.5 & $41.9 \pm 2.8$ & $748 \pm 177$ & $17(4)$ \\
\hline 8 & $23: 22$ & 64.5 & $42.4 \pm 2.4$ & $753 \pm 151$ & $15(5)$ \\
\hline \multicolumn{6}{|c|}{13 March 2002} \\
\hline 9 & $02: 27$ & 65.5 & $43.2 \pm 2.9$ & $829 \pm 143$ & $22(2)$ \\
\hline 10 & $05: 18$ & 64.5 & $45.8 \pm 4.7$ & $995 \pm 325$ & $42(13)$ \\
\hline 11 & $08: 15$ & 64.5 & $42.0 \pm 2.4$ & $756 \pm 141$ & $40(8)$ \\
\hline 12 & $11: 17$ & 64.5 & $42.1 \pm 2.7$ & $746 \pm 131$ & $36(9)$ \\
\hline 13 & $14: 17$ & 64.5 & $42.3 \pm 3.0$ & $759 \pm 198$ & $51(12)$ \\
\hline 14 & $18: 21$ & 64.5 & $42.6 \pm 2.5$ & $754 \pm 141$ & $21(8)$ \\
\hline 15 & $21: 14$ & 64.5 & $41.8 \pm 2.9$ & $729 \pm 159$ & $23(9)$ \\
\hline \multicolumn{6}{|c|}{14 March 2002} \\
\hline 16 & $00: 34$ & 63.5 & $41.9 \pm 2.3$ & $744 \pm 144$ & $17(4)$ \\
\hline Total & & & $42.5 \pm 3.0$ & $776 \pm 188$ & $492(124)$ \\
\hline
\end{tabular}

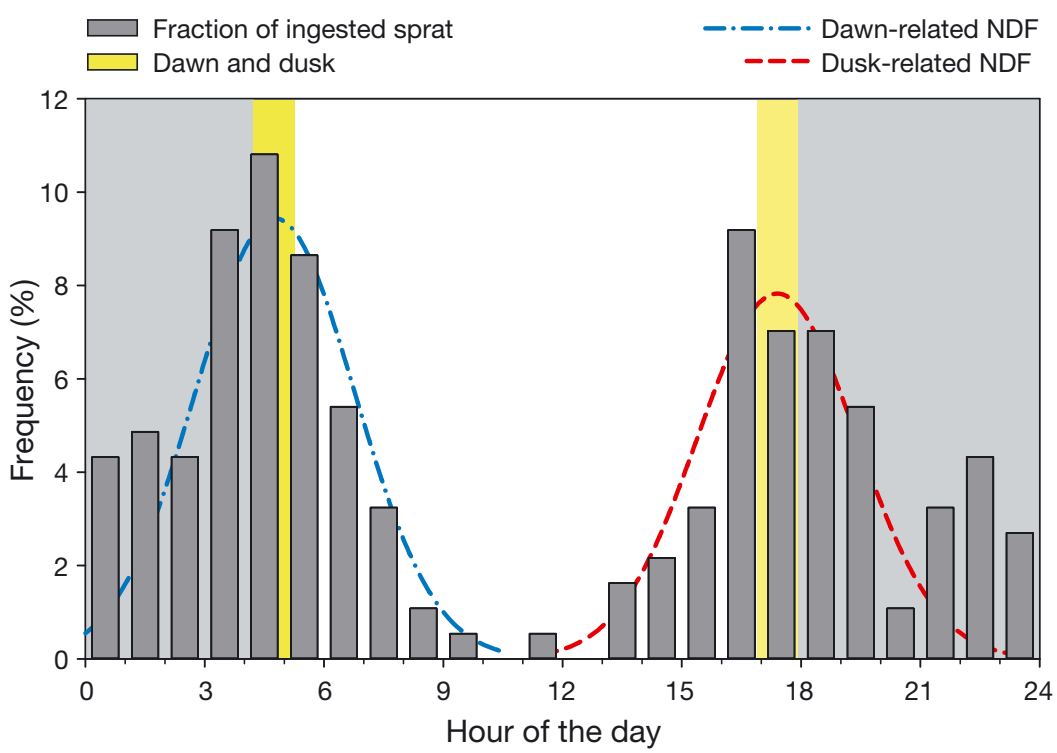

Fig. 7. Diel dynamics of Atlantic cod Gadus morhua feeding on sprat Sprattus sprattus. Columns represent the distribution of all estimated ingestion times ( $\mathrm{n}=194$ sprat) within a $24 \mathrm{~h}$ period prior to sampling of the individual cod. The 2 curves display the normal distribution functions (NDF) for all dawn- and dusk-related ingestion times, respectively, assuming that the actual ingestion takes place in the middle of the dawn and dusk periods and using the mean $\mathrm{SD}$ of the estimates. The rest of the sprat were ingested during the day (1 sprat) or at night. Dawn and dusk are indicated by the transitions between white (day) and grey (night) background gested herring with measured length (only 14 fish) and corrected for estimated shrinkage of $4.5 \% \pm 0.7$ (SD) ranged from 14 to $20 \mathrm{~cm}$ (mean of $16.4 \mathrm{~cm}$ ). This range constituted only the lower half of size distribution of trawled herring (Fig. 3b).

\section{Sprat stomachs}

Almost all 320 sampled sprat stomachs were empty. The exceptions were fish from trawl Stn 2, with 10 out of 20 stomachs containing small amounts of adult Pseudocalanus sp. remains (mean wet content mass: $0.011 \mathrm{~g} ; 0.14 \%$ body mass) and trawl Stn 12, with 6 of 20 stomachs containing copepod remains ( 0.002 g; $0.02 \%$ body mass). Estimation of food consumption rates by use of a GER model (e.g. Bernreuther et al. 2009) to these small amounts of stomach contents therefore gives no meaning.

\section{DISCUSSION}

The crepuscular feeding of cod with $\sim 90 \%$ of the sprat being ingested around dusk or dawn is a general characteristic of piscivorous fishes preying on pelagic, planktivorous fishes performing DVMs (e.g. Hrabik et al. 2006, Jensen et al. 2006). Sprat in the area sampled in the present study also performed DVMs in the feeding season and were distributed in the upper part of the water column at night, where a secondary thermocline at this time of year provided high temperatures above the halocline (Cardinale et al. 2003). This behaviour was explained by maximization of the food processing rate and thus the growth rate (Wurtsbaugh \& Neverman 1988, Levy 1990a,b, Neverman \& Wurtsbaugh 1994, Orlowski 2000). The timing of their DVM with the zooplankton movements was attributed to optimization of the feeding conditions.

\section{Feeding and vertical distribution dynamics of sprat}

With nothing (or occasionally small remains of food) in their stomachs, the sprat in the present study appeared to starve in late winter because their 
main food, planktonic copepods, were still overwintering and at the lowest densities of their annual cycle during the study period (Peters et al. 2006, 2013). This is consistent with the findings of Arrhenius (1998), that sprat in the Baltic Sea feed little and lose body energy during the winter months (November to March), and of Kaartvedt et al. (2009), that sprat in a Norwegian fjord feed on dormant copepods during daytime, or do not feed at all. It furthermore fits in with the general tendency that planktivorous fishes in the temperate zone are food-limited during overwintering (Byström et al. 2006).

Previous laboratory work has shown that a number of fishes on low ration, or starved, select colder temperatures compared to well-fed individuals (Comeau et al. 2002). A generally accepted $Q_{10}$ value of $\sim 2.2$ for metabolic rates (Schmidt-Nielsen 1983, Willmer et al. 2000) provides a reduction in metabolic rate of $33 \%$ when sprat are located above the thermocline at $3^{\circ} \mathrm{C}$, compared to the bottom at $8^{\circ} \mathrm{C}$ in the present study. There is consequently a bioenergetic incentive for the starving sprat to stay high in the water column during the winter to minimize energy expenditures by performing DVMs into the upper uniform layer of low temperature in the dark hours when predation risk is reduced (Brett 1971, Méndez \& Wieser 1993).

Being a physostome fish, the vertical distribution of sprat may be affected in 2 ways. These fish lack gas secreting glands for adjustment of the swimbladder at different depths, so the swimbladder becomes successively compressed at increasing depth making the fish negatively buoyant in deeper water (Solberg \& Kaartvedt 2014). Using bottom mounted, upward facing echosounders during wintertime in Bunnefjorden, Norway, Kaartvedt et al. (2009) tracked individual sprat and showed that the fish continuously swam up and down at depths $>55 \mathrm{~m}$, and this way maintained the same depth over time. This was interpreted as sinking due to negative buoyancy followed by compensatory ascent, which implies extra metabolic costs compared to a situation of neutral buoyancy (Huse \& Ona 1996, Speers-Roesch et al. 2004). In the present study, the ascent of sprat from depths of 55 to $60 \mathrm{~m}$ at dusk when predation risk is reduced may therefore also be due to a strategy of minimizing swimming costs by reducing negative buoyancy. Secondly, Kaartvedt et al. (2009), Solberg \& Kaartvedt (2014) and Solberg et al. (2015) tracked individual sprat performing short excursions to the surface at night and ascribed this swimming behaviour to refilling the swimbladder by gulping atmospheric air. However, even in situations of inverse DVM, with sprat aggregating in deep water at night, surfacing did not seem to impact the vertical distribution pattern at large (Solberg \& Kaartvedt 2014). It is therefore doubtful whether surfacing behaviour can explain the vertical distribution dynamics observed in the present study in the Baltic Sea.

The probability of suffering winter starvation mortality increases with decreasing fish size (Schultz \& Conover 1999, Byström et al. 2006). This is because the relationship between body mass and the energy reserve accumulated during spring, summer and autumn is hyperallometric (power $>1$ ), but hypoallometric (power $<1$ ) between body mass and metabolic rate, implying that larger fish are able to subsist longer on their reserves compared to their smaller conspecifics at a given temperature (Schultz \& Conover 1999). The higher percentage of the small, YOY sprat in the pelagic trawl catches above the halocline compared to the bottom trawl catches in the dark hours (Fig. 3a) may therefore be the result of a higher incentive for the smaller fish to seek and stay at lower temperature.

From trawl catches in the feeding season, Cardinale et al. (2003) found differences in the length frequency distribution of herring at different water depths during the day as well as at night, with larger individuals being more abundant near the bottom. However, in contrast to the results of the present study, they did not report any differences for sprat. Still, Fig. 8 of Cardinale et al. (2003) indicates that the percentage of small sprat in the pelagic catches during the night is higher compared with the size composition of the catches close to the bottom. If statistically significant, it might be argued that during the night when predation risk is reduced, the sprat seek warmer water to accelerate food consumption or processing and maximize their energy stores for the coming winter (e.g. Levy 1990a,b). Busch \& Mehner (2012) observed a similar pattern for coregonids and estimated that small fish profit from a faster and earlier ascent at dusk by increasing their daily ration by $\sim 8 \%$ relative to fish that would migrate together with the main population. On this basis, Busch \& Mehner (2012) recommended that the size-specific variability in individual migration trajectories must be considered in future studies addressing ultimate causes of DVM.

During wintertime in Bunnefjorden, the hydroacoustics showed a bimodal vertical distribution of sprat (Solberg et al. 2015). In the winters during which the sprat were actually feeding, this distribution was reflected in their size range in that body size increased with depth. Supported by observed stomach contents, this distribution was partly explained by the smaller, YOY individuals being more active 
feeders in the intermediate waters compared to their older conspecifics. The Bunnefjorden is a deep fjord with a thick, hypoxic bottom layer, the upper part of which probably works as a refuge from gadoid predators. The intermediate water is warmer than bottom and surface waters. The distribution pattern could therefore be explained by 2 different fitness optimization strategies, with the YOY sprat benefiting most by maximizing growth rate, and the adults by minimizing mortality rate. These different strategies were used in a stochastic dynamic optimization model developed by Rosland \& Giske (1994) for the depth distribution of juveniles and adults of the small mesopelagic planktivorous fish Maurolicus muelleri in a winter situation. The distribution pattern could, however, also be explained by different internal states such as hunger coupled with the energy storage for overwintering (Solberg et al. 2015), the latter generally increasing with body size cf. the discussion above. The studies on sprat in Bunnefjorden thus demonstrate how biotic and abiotic variables may interact in controlling the overwintering ecology of sprat (Solberg et al. 2015).

\section{Feeding and vertical distribution dynamics of cod}

The narrow diet niche width of the sampled cod reflected the low diversity of appropriate prey in the Baltic Sea. Sprat constituted $>90 \%$ of the ingested energy, and herring most of the remaining part, leaving other prey (including invertebrates) as an almost insignificant portion of the diet. Smaller cod $(<25 \mathrm{~cm})$ probably fed mostly on bottom-dwelling invertebrates. At least, they were almost absent in the pelagic catches (Fig. 3c), indicating that they did not forage on sprat and therefore did not participate in the vertical foraging movements.

The size range and frequency distribution of sprat ingested by the sampled cod matched well that of sprat caught by bottom trawl (Fig. 3a). In contrast, the size range (14 to $20 \mathrm{~cm}$ ) of ingested herring covered only the lower half of the length distribution of herring in the trawl catches (Fig. 3b). The latter observation is in accordance with field studies on prey size preference of cod, where the maximum prey fish length in stomachs of cod of the same size range as in the present study was $\sim 20 \mathrm{~cm}$ for a mixture of prey, including clupeids (Lilly \& Fleming 1981, Scharf et al. 2000, Pinnegar et al. 2003). Cod longer than $50 \mathrm{~cm}$ were rare, so herring above $20 \mathrm{~cm}$ appeared to have been at least partly released from predation pressure by cod.
The estimated feeding level $f \sim 0.40$ for cod was obtained irrespective of methodology and subset of data by use of the GER model to cod stomach content data. This level is close to the median value 0.43 (SD $=0.07$ ) estimated by Armstrong \& Schindler (2011) across 66 populations of 38 fish species. It is well above a typical maintenance level of $\sim 0.20$ (Hanson et al. 1997) and 0.20 to 0.25 estimated from laboratory experiments on the 2 gadoids whiting Merlangius merlangus and saithe Pollachius virens fed natural prey fishes (Andersen \& Riis-Vestergaard 2003).

Thus, in contrast to sprat, the energy balance of cod appeared to be positive and the feeding conditions therefore favourable during wintertime. If so, the optimal behaviour between feeding events should be to stay at high temperature to maximize the food processing rate (e.g. Levy 1990a,b). However, higher temperatures imply lower levels of dissolved oxygen (Fig. 2) and chronic hypoxia is known to depress food consumption and growth rates of fish (Chabot \& Dutil 1999), probably by reducing the aerobic scope (maximum metabolic rate - standard metabolic rate) (Jordan \& Steffensen 2007). The optimum conditions for food processing are therefore believed to have been determined by a trade-off between temperature and oxygen saturation in the environmental settings of the Bornholm Basin. In laboratory experiments at $10^{\circ} \mathrm{C}$ on cod of body size similar to the present study, significant effects of dissolved oxygen on growth were observed below $65 \%$ saturation, with the estimated critical level between 65 and $73 \%$ (Chabot \& Dutil 1999). Also, the GER was unaffected or only marginally affected at $65 \%$ saturation (Brach 1999) whereas it was significantly slower at 55 and $40 \%$ saturation as compared with normoxia (Chabot et al. 2015).

Considering the positive energy balance and the trade-off between temperature and oxygen saturation, the estimated position in the water column of cod at $64 \%$ oxygen saturation and $5.5^{\circ} \mathrm{C}$, apart from (feeding) raids upwards in the water column (Figs. $2 \& 6 \mathrm{~b}$ ), appears optimal in terms of maximizing the food processing rate. Higher temperatures would imply lowering of the oxygen saturation to levels that significantly depress the physiological processes in the fish.

\section{SUMMARY AND CONCLUSIONS}

The different energy balances of the 2 species explained their respective temperature preferences. Also, there appeared to be a trade-off between temperature and oxygen saturation for cod profiting from the accessibility of sprat prey by staying at the tem- 
perature-oxygen combination that maximizes food processing (e.g. Claireaux et al. 2000). Schooling of sprat at the same depth as cod in the daytime appeared to be an effective method of protection against predation, as cod were not successful in capturing sprat during this period (Fig. 7) (Magurran 1990, Pitcher 1993, Pitcher \& Parrish 1993). Reduction of standard metabolic costs of the starving sprat may constitute the adaptive background for moving to the upper water layers of lower temperature during the dark hours, when predation risk is reduced. The reduction of swimming costs by staying high in the water column and reducing the negative buoyancy at night further contribute to lowering total metabolic costs. Hence, a trade-off between predation and winter starvation mortality may explain the DVM behaviour of sprat under these environmental conditions.

Through a focus on a typical winter situation, it has been possible to acquire new mechanistic knowledge about vertical predator-prey interactions in the most important basin of the Baltic Sea. The adaptive behaviour of predator and prey was explained by combining diel predation patterns with vertical fish distribution dynamics, the setting of the physical environment, and fitness optimization based on bioenergetics and relevant trade-offs. In this way, the present study presents an avenue to unveil the biological mechanisms on a small scale that give rise to specific observed predator-prey interactions on a large scale. Use of the integrated methodologies applied here to obtain information from other seasons and locations in the basin and beyond should ultimately contribute to establishment of aggregate functional response of cod in the Baltic Sea. This approach should prove useful for forecasting the upper trophic dynamics in scenarios enforced by climate changes, and further provide important tradeoffs for fitness optimization in life history models.

Acknowledgements. We thank the crew and the scientific staff onboard the RV 'Dana' for a well conducted cruise, Ole M. Larsen for laboratory analysis of the cod stomach contents, Dorthe Frandsen for measurement of the prey energy densities, and B. Huwer for providing Fig. 1. We also thank 3 thoughtful anonymous reviewers for providing helpful comments that improved the manuscript. The work on data analyses and manuscript preparation has been financially supported by the INSPIRE Project, which is a part of BONUS, the joint Baltic Sea research and development programme (Art 185), funded jointly from the European Union's Seventh Programme for Research, Technological Development and Demonstration and national funding institutions. The study was further co-funded by the PRIME TRADEOFFS project under the COFASP ERA-NET partnership (grant agreement no. 321553).

\section{LITERATURE CITED}

Andersen NG (2012) Influences of potential predictor variables on gastric evacuation in Atlantic cod Gadus morhua feeding on fish prey: parameterization of a generic model. J Fish Biol 80:595-612

* Andersen NG, Beyer JE (2005a) Mechanistic modelling of gastric evacuation applying the square root model to describe surface-dependent evacuation in predatory gadoids. J Fish Biol 67:1392-1412

Andersen NG, Beyer JE (2005b) Gastric evacuation of mixed stomach contents in predatory gadoids: an expanded application of the square root model to estimate food rations. J Fish Biol 67:1413-1433

Andersen NG, Beyer JE (2008a) Precision of ingestion time and evacuation predictors for individual prey in stomachs of predatory fishes. Fish Res 92:11-22

Andersen NG, Beyer JE (2008b) Predicting ingestion times of individual prey from information about stomach contents of predatory fishes in the field. Fish Res 92:1-10

Andersen NG, Riis-Vestergaard J (2003) The effects of food consumption rate, body size and temperature on net food conversion efficiency in saithe and whiting. J Fish Biol 62:395-412

Andersen NG, Chabot D, Couturier CS (2016) Modelling gastric evacuation in gadoids feeding on crustaceans. J Fish Biol 88:1886-1903

Armstrong JB, Schindler DE (2011) Excess digestive capacity in predators reflects a life of feast and famine. Nature 476:84-87

Arrhenius F (1998) Food intake and seasonal changes in energy content of young Baltic Sea sprat (Sprattus sprattus L.). ICES J Mar Sci 55:319-324

* Bernreuther M, Temming A, Herrmann JP (2009) Effect of temperature on the gastric evacuation in sprat Sprattus sprattus. J Fish Biol 75:1525-1541

Blaxter JHS (1975) The role of light in the vertical migration of fish - a review. In: Evans GC, Bainbridge R, Racham O (eds) Light as an ecological factor. Blackwell Scientific Publications, Oxford, p 189-210

Braaten B (1984) Growth of cod in relation to fish size and ration level. Flodevigen Rapportserie 1:677-710

Brach H (1999) Experimente zur nahrungsaufnahme und zum Wachstum von Dorschen bei unterschiedlichen Sauerstoffbedingungen. MSc thesis, Christian-AlbrechtsUniversität zu Kiel (Kiel University)

Brett JR (1971) Energetic responses of salmon to temperature: a study of some thermal relations in physiology and freshwater ecology of sockeye salmon (Oncorhynchus nerka). Am Zool 11:99-113

* Busch S, Mehner T (2012) Size-dependent patterns of diel vertical migration: smaller fish may benefit from faster ascent. Behav Ecol 23:210-217

Byström P, Andersson J, Kiessling A, Eriksson LO (2006) Size and temperature dependent foraging capacities and metabolism: consequences for winter starvation mortality in fish. Oikos 115:43-52

Cardinale M, Casini M, Arrhenius F, Håkansson N (2003) Diel spatial distribution and feeding activity of herring (Clupea harengus) and sprat (Sprattus sprattus) in the Baltic Sea. Aquat Living Resour 16:283-292

Casini M, Hjelm J, Molinero JC, Lövgren J and others (2009) Trophic cascades promote threshold-like shifts in pelagic marine ecosystems. Proc Natl Acad Sci USA 106:197-202 
Chabot D, Dutil JD (1999) Reduced growth of Atlantic cod in non-lethal hypoxic conditions. J Fish Biol 55:472-491

Chabot D, Behrens J, Andersen NG (2015) Digesting in hypoxia: impact on gastric evacuation rate of Atlantic cod, Gadus morhua. ICES CM 2015/R:08, ICES Annual Science Conference, 21-25 Sep 2015, Copenhagen

Claireaux G, Webber DM, Lagadère JP, Kerr SR (2000) Influence of water temperature and oxygenation on the aerobic metabolic scope of Atlantic cod (Gadus morhua). J Sea Res 44:257-265

Clark CW, Levy DA (1988) Diel vertical migrations by juvenile sockeye salmon and the antipredation window. Am Nat 131:271-290

Comeau LA, Campana SE, Chouinard GA (2002) Timing of Atlantic cod (Gadus morhua L.) seasonal migrations in the southern Gulf of St. Lawrence: interannual variability and proximate control. ICES J Mar Sci 59:333-351

Didrikas T, Hansson S (2004) In situ target strength of the Baltic Sea herring and sprat. ICES J Mar Sci 61:378-382

Ducklow H, Dickson A (1994) Protocols for the joint global ocean flux study (JGOFS) core measurements. IOC manuals and guides No. 29. UNESCO, Paris. www.jodc.go. jp/info/ioc_doc/Manual/m029.pdf

Efron B, Tibshirani RJ (1993) An introduction to the bootstrap. CRC Press, Boca Raton, FL

Eggers DM (1978) Limnetic feeding behavior of juvenile sockeye salmon in Lake Washington and predator avoidance. Limnol Oceanogr 23:1114-1125

Englund G, Leonardsson K (2008) Scaling up the functional response for spatially heterogeneous systems. Ecol Lett 11:440-449

Farrell AP, Thorarensen H, Axelson M, Crocker CE, Gamperl AK, Cech JJ (2001) Gut blood flow in fish during exercise and severe hypercapnia. Comp Biochem Physiol A Mol Integr Physiol 128:551-563

Fässler SMM, Gorska N, Ona E, Fernandes PG (2008) Differences in swimbladder volume between Baltic and Norwegian spring-spawning herring: consequences for mean target strength. Fish Res 92:314-321

Floeter J, Temming A (2003) Explaining diet composition of North Sea cod (Gadus morhua): prey size preference vs. prey availability. Can J Fish Aquat Sci 60:140-150

Foote KG (1987) Fish target strengths for use in echo integrator surveys. J Acoust Soc Am 82:981-987

Frank KT, Petrie B, Choi JS, Leggett WC (2005) Trophic cascades in a formerly cod-dominated ecosystem. Science 308:1621-1623

Golley FB (1961) Energy values of ecological materials. Ecology 42:581-584

Griffith WE (1976) Feeding and gastric evacuation in perch (Perca fluviatilis L.). Mauri Ora 4:19-34

Hanson PC, Johnson TB, Schindler DE, Kitchell JF (1997) Fish bioenergetics 3.0. Report No. WISCU-T-97-001, University of Wisconsin Sea Grant Institute, Madison, WI

Hislop JRG, Robb AP, Bell MA, Armstrong DW (1991) The diet and food consumption of whiting (Merlangius merlangus) in the North Sea. ICES J Mar Sci 48:139-156

Hrabik TR, Jensen OP, Martell SJD, Walters CJ, Kitchell JF (2006) Diel vertical migration in the Lake Superior pelagic community. I. Changes in vertical migration of coregonids in response to varying predation risk. Can J Fish Aquat Sci 63:2286-2295

Hunsicker ME, Ciannelli L, Bailey KM, Jeffrey A, Buckel JA, White JW (2011) Functional responses and scaling in predator-prey interactions of marine fishes: contem- porary issues and emerging concepts. Ecol Lett 14: 1288-1299

* Huse I, Ona E (1996) Tilt angle distribution and swimming speed of overwintering Norwegian spring spawning herring. ICES J Mar Sci 53:863-867

ICES (1991) Manual for the ICES North Sea stomach sampling project in 1991. ICES CM 1991/G:3, ICES, Copenhagen

ICES (2009) Manual for the Baltic international acoustic survey (BIAS). Addendum 2: WGBIFS BIAS manual 2009, version 0.81. Baltic International Fish Survey Working Group (WGBIFS), ICES, Copenhagen

Jensen OP, Hrabik TR, Martell SJD, Walters CJ, Kitchell JF (2006) Diel vertical migration in the Lake Superior pelagic community. II. Modeling trade-offs at an intermediate trophic level. Can J Fish Aquat Sci 63:2296-2307

Jobling M (1988) A review of the physiological and nutritional energetics of cod, Gadus morhua L., with particular reference to growth under farmed conditions. Aquaculture 70:1-19

*Johansen GO, Bogstad B, Mehl S, Ulltang Ø (2004) Consumption of juvenile herring (Clupea harengus) by cod (Gadus morhua) in the Barents Sea: a new approach to estimating consumption in piscivorous fish. Can J Fish Aquat Sci 61:343-359

Johnsen T (1981) Otolittsoner og vekstprosesser hos torsk (Gadus morhua L.) i Balsfjorden. MSc thesis, University of Tromsø

Jordan AD, Steffensen JF (2007) Effects of ration size and hypoxia upon specific dynamic action (SDA) in the cod. Physiol Biochem Zool 80:178-185

Kaartvedt S, Røstad A, Klevjer TA (2009) Sprat Sprattus sprattus can exploit low oxygen waters for overwintering. Mar Ecol Prog Ser 390:237-249

K Köster FW, Möllmann C, Neuenfeldt S, St John MA, Plikshs M, Voss R (2001) Developing Baltic cod recruitment models. I. Resolving spatial and temporal dynamics of spawning stock and recruitment for cod, herring, and sprat. Can J Fish Aquat Sci 58:1516-1533

Lampert W, Sommer U (2007) Limnoecology: the ecology of lakes and streams. Oxford University Press, Oxford

* Levy DA (1990a) Reciprocal diel vertical migration behaviour in planktivores and zooplankton in British Columbia lakes. Can J Fish Aquat Sci 47:1755-1764

KLevy DA (1990b) Sensory mechanism and selective advantage for diel vertical migration behaviour in juvenile sockeye salmon, Oncorhynchus nerka. Can J Fish Aquat Sci 47:1796-1802

Lilly GR, Fleming AM (1981) Size relationships in predation by Atlantic cod, Gadus morhua, on capelin, Mallotus villosus, and sand lance, Ammodytes dubius, in the Newfoundland area. NAFO Sci Counc Stud 1:41-45

Link JS (2010) Ecosystem-based fisheries management: confronting trade-offs. Cambridge University Press, Cambridge

Magurran AE (1990) The adaptive significance of schooling as an anti-predator defence in fish. Ann Zool Fenn 27: $51-66$

Méndez G, Wieser W (1993) Metabolic responses to food deprivation and refeeding in juveniles of Rutilus rutilus (Teleostei: Cyprinidae). Environ Biol Fishes 36:73-81

Neuenfeldt S, Beyer JE (2006) Environmentally driven predator-prey overlaps determine the aggregate diet of the cod Gadus morhua in the Baltic Sea. Mar Ecol Prog Ser 310:151-163 
Neverman D, Wurtsbaugh WA (1994) The thermoregulatory function of diel vertical migration for a juvenile fish, Cottus extensus. Oecologia 98:247-256

Nilsson LAF, Thygesen UH, Lundgren B, Nielsen BF, Nielsen JR, Beyer J (2003) Vertical migration and dispersion of sprat (Sprattus sprattus) and herring (Clupea harengus) schools at dusk in the Baltic Sea. Aquat Living Resour 16:317-324

Orlowski A (2000) Diel dynamics of acoustic measurements of Baltic fish. ICES J Mar Sci 57:1196-1203

Paine RT (1966) Endothermy in bomb calorimetry. Limnol Oceanogr 11:126-128

Paine RT (1980) Food webs: linkage, interaction strength and community infrastructure. The third Tansley lecture. J Anim Ecol 49:667-685

Pedersen J, Hislop JRG (2001) Seasonal variations in the energy density of fish in the North Sea. J Fish Biol 59: 380-389

Pennington M (1985) Estimating the average food consumption by fish in the field from stomach contents data. Dana 5:81-86

* Peters J, Renz J, van Beusekom J, Boersma M, Hagen W (2006) Trophodynamics and seasonal cycle of the copepod Pseudocalanus acuspes in the Central Baltic Sea (Bornholm Basin): evidence from lipid composition. Mar Biol 149:1417-1429

* Peters J, Dutz J, Hagen W (2013) Trophodynamics and lifecycle strategies of the copepods Temora longicornis and Acartia longiremis in the central Baltic Sea. J Plankton Res 35:595-609

Pinnegar JK, Trenkel VM, Tidd AN, Dawson WA, Du Buit $\mathrm{MH}$ (2003) Does diet in Celtic Sea fishes reflect prey availability? J Fish Biol 63(Suppl A):197-212

Pitcher TJ (ed) (1993) Behaviour of teleost fishes, $2^{\text {nd }}$ edn. Fish and Fisheries Series 7. Chapman \& Hall, London

Pitcher TJ, Parrish JK (1993) Functions of shoaling in teleost fishes. In: Pitcher TJ (ed) Behaviour of teleost fishes, 2nd edn. Chapman \& Hall, London, p 363-439

R Core Team (2016) R: a language and environment for statistical computing. R Foundation for Statistical Computing, Vienna

Editorial responsibility: Alejandro Gallego,

Aberdeen, UK
Rindorf A, Gislason H, Lewy P (2006) Prey switching of cod and whiting in the North Sea. Mar Ecol Prog Ser 325: 243-253

Rose GA, Leggett WC (1990) The importance of scale to predator-prey spatial correlations: an example of Atlantic fishes. Ecology 71:33-43

* Rosland R, Giske J (1994) A dynamic optimization model of the diel vertical distribution of a pelagic planktivorous fish. Prog Oceanogr 34:1-43

Scharf FS, Juanes F, Rountree RA (2000) Predator sizeprey size relationships of marine fish predators: interspecific variation and effects of ontogeny and body size on trophic-niche breadth. Mar Ecol Prog Ser 208: 229-248

Scheuerell MD, Schindler DE (2003) Diel vertical migration by juvenile sockeye salmon: empirical evidence for the antipredation window. Ecology 84:1713-1720

Schmidt-Nielsen K (1983) Animal physiology: adaptation and environment, 3rd edn. Cambridge University Press, New York, NY

Schultz ET, Conover DO (1999) The allometry of energy reserve depletion: test of a mechanism for size-dependent winter mortality. Oecologia 119:474-483

Solberg I, Kaartvedt S (2014) Surfacing behavior and gas release of the physostome sprat (Sprattus sprattus) in icefree and ice-covered waters. Mar Biol 161:285-296

Solberg I, Røstad A, Kaartvedt S (2015) Ecology of overwintering sprat (Sprattus sprattus). Prog Oceanogr 138: 116-135

Speers-Roesch B, Lingwood D, Stevens ED (2004) Effects of temperature and hydrostatic pressure on routine oxygen uptake of the bloater (Coregonus hoyi). J Gt Lakes Res 30:70-81

* Turesson H, Brönmark C (2007) Predator-prey encounter rates in freshwater piscivores: effects of prey density and water transparency. Oecologia 153:281-290

Willmer P, Stone G, Johnston IA (2000) Environmental physiology of animals. Blackwell Science, Oxford

*Wurtsbaugh WA, Neverman D (1988) Post-feeding thermotaxis and daily vertical migration in a larval fish. Nature 333:846-848

Submitted: February 27, 2017; Accepted: August 30, 2017 Proofs received from author(s): October 30, 2017 